\title{
Resilience among psychotherapists: Personal coping and environmental factors
}

Harishankar Moosath*

\begin{abstract}
:
This article explores the relationships between resilience and occupational stress among psychotherapists. Using a phenomenological paradigm, ten Psychotherapists in clinical practice were interviewed to explore the intrinsic and extrinsic factors that enable them to cope with stress as well as their perception of environmental factors that contribute to resilience. Thematic analysis was used to capture personal coping and environmental factors that contribute to resilience. The findings are discussed and implications for further research indicted.
\end{abstract}

Keywords: Resilience, Coping with stress, Psychotherapists

\section{Introduction}

Narrative accounts of resilience in popular literature have often grabbed our interest and enthusiasm. Anne Frank's (1952) Diary of a Young Girl, and more recently works such as Frank McCourt's (1996) Angela's Ashes, Denise Chong's (2000) The Girl in the Picture have provided evidence of resilience in lives lived, but without the rigor of structured qualitative analyses to understand the mechanisms which promote healthy outcomes.

In Greek mythology, the myth of Chiron introduces the paradoxical concept of the wounded healer. Chiron, a centaur and a healer suffers from an incurable wound. The myth suggests that only

\footnotetext{
* Research scholar, Department of Clinical psychology, NIMHANS, Bangalore, India ; harishankarmoosath@yahoo.com
} 
through being wounded can an individual truly heal others. (Groesbeck, 1975; Kirmayer, 2003). The concept of the wounded healer is among one of the Jungian archetypes and can be described as a complex interaction between a therapist and the client. According to this dynamic, the therapist's own wounds may be activated but they can potentially be used in turn to encourage selfhealing in the client. (Groesbeck, 1975; Miller \& Baldwin, 2000; Sedgwick, 2001)

Mental health professionals, due to the nature of their work, are particularly vulnerable to emotional exhaustion and fatigue. However, the question of how the healer heals himself and continues to be a resilient professional has not received much attention and is the focus of this research study.

Career resilience as a concept looks at what makes people sustain in their occupation. Collard, Epperheimer and Saign (1996) present several definitions of career resilience. One of these is "the ability to adapt to changing circumstances, even when the circumstances are discouraging or disruptive" (Collard et al., 1996, p. 33). Career selfreliance refers to individual career self-management and taking responsibility for one's own career and growth, while maintaining commitment to the organization's success. Waterman, Waterman and Collard (1994) believe that a career resilient work force is "a group of employees who not only are dedicated to the idea of continuous learning but also stand ready to reinvent themselves to keep pace with change, who take responsibility for their own career management, and last but not least, who are committed to the company's success" (Waterman et al. 1994, p.88).

Brown (1996) identified four elements of career resilience. They are self-confidence, the need for achievement, the willingness to take risks, and the ability to act independently and cooperatively, depending on the situation. Behaviors that demonstrate these factors include: easily adjusting to changes; taking initiative to do what is needed to achieve career goals; articulating one's ideas even when unpopular; seeking projects that would require learning new skills; and being innovative. He also believes that organizations have a significant role and responsibility in providing an environment that helps build career resilience in its workers. Brown (1996) states that the concept of career resilience is 
applicable to all workers at all levels and to organizations of varying sizes in all industries including education.

\section{Research Objectives}

\section{Major Research Objective}

To study how psychotherapists handle occupational stress positively.

\section{Specific Research Objectives}

To explore intrinsic and extrinsic factors that enable psychotherapists to cope with occupational stress.

To identify factors within their environment that psychotherapists perceive as supportive to developing resilience.

\section{Resilience among Mental Health Professionals.}

Clark (2009) studied resilience among practicing family therapists using a grounded theory paradigm and found that a deep sense of respect for self and others, as well as maintaining an I-position which involves maintaining a distinct sense of self and adhere to personal convictions even when pressurized by others to do otherwise contributed to resilience. Also a sense of emotional attunement, which is being aware of one's emotions and enjoying what they did added to resilience. Discussing 'troubled' clients with peers and coworkers also helped them to deal with their everyday stressors. Finding meaning in their profession and also creating a supportive environment at work were among the themes that evolved.

Zur (2011) in his article states some of the factors that contribute to therapist burnout, which include emotional depletion, isolation, helplessness and sense of inefficiency, depression, sadness and vicarious traumatization, confusion, distraction, inability to shut off the therapeutic stance, conflicting clinical, ethical, and legal considerations, the threat of lawsuits as some of the factors that are hazardous to the profession of a therapist. This, if not negotiated, may even lead to burnout. He also suggests some measures to avoid burnout which include regular supervision, ethical practices 
of therapy, continuing education and being involved in non professional activities, and creating a work- family balance.

Emery and Wally (2009) found that higher levels of personal accomplishment were significantly associated with a lower annual income, not having a mixed caseload, having more personal resources, and endorsing lower levels of therapist beliefs related to inflexibility and control among clinical psychologists.

Johnston (2006) analyzed factors contributing to resilience in a trauma therapist working with children for over 22 years. He found that the therapist's meaning making around the notions of identity, resistance, spirituality, hope, joy and the professional gaze have contributed to sustaining her in assisting children in their healing journey and resilience development.

Liney and Josef (2007) studied factors contributing to resilience and wellbeing among psychotherapists. They found that personal therapy, supervision, therapeutic training and practical orientation, length of therapy career, current therapy workload, gender, and personal trauma history were a part of the occupational factors that contributed to therapist resilience and well being. Psychological factors that contributed to resilience included a sense of coherence, social support, empathy.

Physicians too have to face considerable stress in their occupation. Kumar et al (2008) found the following factors leading to resilience in physicians 1) attitudes and perspectives, which include valuing the physician role, maintaining interest, developing self-awareness, and accepting personal limitations; 2) balance and prioritization, which include setting limits, taking effective approaches to continuing professional development, and honoring the self; 3) practice management style, which includes sound business management, having good staff, and using effective practice arrangements; and 4) supportive relations, which include positive personal relationships, effective professional relationships, and good communication.

Alexander et al (2011) found that physicians felt immensely motivated by the fact that they were helping someone in need. They were sustained by a deep appreciation and respect for the population they served, an intellectual engagement with the work 
itself, and the ability to control their own working hours (often by working part-time in the field of interest). In their clinical work, they recognized and celebrated small gains and were not overwhelmed by the larger context of social disadvantage.

It can be seen that mental health professionals survive their occupational stress using various strategies and emerge as resilient professionals. Some of them are related to their work, for example the satisfaction of helping a client, while others are related to the professionals themselves for example their attitudes towards work.

\section{Methodology}

\section{Research Design}

A qualitative research method was chosen for the study, because it was valued as a method of inquiry for exploratory studies to "identify variables and generate hypotheses germane to populations and groups that have been previously overlooked" (Merchant \& Dupuy, 1996, p. 539).

\section{Research Paradigm}

The current study followed the salutogenic paradigm (Antonovsky, 1987), which falls under the phenomenological research paradigm. The term "salutogenesis," is derived from salus, the Latin expression for health and well-being, and emphasizes on health rather than on disease (i.e., the pathogenesis emphasis). Antonovsky, 1987 proposed a paradigm to account for the unexpected fact thatsome people stay relatively well, despite experiencing major challenges in their lives. The salutogenic paradigm rejects the dichotomous classification of people either as healthy or diseased. It aims at exploring the origin of health rather than trying to explain the causes of disease and disabilities. It seeks to explore how we can live well with our stressors and use them to our benefits.

\section{Sampling}

The sample for the study was selected through purposive sampling. This type of sampling is based on the assumption that because the researcher wants to discover, understand, and gain 
insight, he or she must select a sample from which the most can be learned (Chein, 1981).

\section{Participants}

Psychotherapists working in the mental health profession for at least 5 years in the cities of Bangalore or Mumbai were selected for the study who met the following inclusion criteria: Mental health Professionals of agencies (hospitals and rehabilitation settings) offering therapy for mentally ill individuals and their families. Respondents with a postgraduate degree in psychology, social work or psychosocial rehabilitation. Respondents currently working in the setting with a minimum work experience of five years.

Mental health professionals who are engaged in an alternative profession (such as training or teaching) and psychotherapists with a past history of any psychological illness or physical disability were excluded from the study.

\section{Procedure for data collection}

Based on available literature on resilience, an interview guide was formulated which was validated by an expert. A pilot study was conducted following which necessary changes were made to the interview guide. Psychotherapists who met the inclusion criteria were contacted and approached for participation. Informed consent for participating in the study was obtained from them and an indepth interview was conducted. The interviews were audio recorded with the participant's consent and were later transcribed. Since the interviews were in English, there was no need of translating them.

\section{Data Analysis}

Analysis of the transcribed interviews was carried out using Thematic Analysis. Thematic analysis is a process of encoding qualitative data in a way that identifies and analyses patterns and themes. A theme can be defined as a pattern in the data that at the very least describes and organizes and at the very most interprets aspects of the phenomenon (Boyatzis, 1998). 


\section{Credibility of the study}

To establish validity in the results of the study, the following deliberate measures were taken: Prolonged engagements with the participants occurred to understand the topic of the study in detail and to avoid any misinterpretations. The transcribed interviews were sent back to the participants for cross validation. Peer validation was done by asking a peer to generate themes from the transcribed interviews and then comparing them with the obtained themes. The data, categories, themes, interpretations and conclusions were tested with the participants. They were given an opportunity to react to them and point out any discrepancies between their responses and the results.

\section{Results and Discussion}

The thematic analysis of the transcribed interviews revealed two global themes: Intrinsic factors contributing to resilience and Extrinsic factors contributing to resilience.

\section{Intrinsic Factors contributing to Resilience}

This broad theme focuses on the intrinsic factors that help psychotherapists maintain professional vitality and sustain in the profession. It refers to factors that are in the participant's control and may have existed before they entered this profession.

A passion for the profession. All the 10 participants mentioned having a strong passion for the profession. This was worded as passion, a deep commitment, a strong interest etc. by the participants. It was something that motivated them to work, something that made work seem less tedious. To quote P5,

"If you are passionate about what you do, then work doesn't seem like work. You enjoy it, cherish it"

\section{As P7 mentions,}

"I guess it's the passion that is there within me that keeps me alive. No matter how stressed you are, you know that there's this passion inside you. A deep driving force that gives you a different perspective... Stressors don't present themselves as stressors then, you find them challenging." 
A sense of purpose. Seven out of 10 participants referred to facilitating good mental health as their purpose in life. A sense of purpose is a deep belief that one's life has meaning and that one has a place in the universe (Werner \& Smith, 1992). It was stated by the participants that this belief was what gave meaning to their lives despite the challenges. Also, this sense of purpose seemed to be the force behind their persistence.

As P1 mentions,

"I was diagnosed with major depression in my teenage. It was a major perspective change. It helped me understand what being depressed can actually feel like. I realized that I needed to decide what I really wanted out of life and focus on that."

To quote another participant (P8),

"I guess this is what I have always wanted to become. Umm I don't think I would be as comfortable in any other setting as mental health. On a more philosophical note, I derive meaning from therapy."

Personality Factors. This subtheme refers to factors characteristic of the personality of the participants, for example humor, frustration tolerance, detachment etc .

High Frustration Tolerance. Participants stressed the importance of being patient with the client and developing a high tolerance for client's issues and inertia. Being patient involves not being vulnerable to the client's behaviour. It involved a sense of unconditional acceptance.

P1 puts it in this way,

"As a practicing REBT therapist, I tend to practice what I preach. A high frustration tolerance is essential to help the clients and prevent oneself from being carried away with the issues clients bring to your table."

Humor. Participants also talked about the benefits of humor. Humor is the individual's ability to find the comic in the tragic. According to the participants, it is something that often keeps them going. It is interesting to note that all ten participants found humor beneficial and as contributing to their resilience. To quote P4, 
"Humor certainly helps me to deal with the clients. It helps to sustain the rapport and also eases out the tension if any. It also helps to bring out the best in me."

Skills related to the profession. Participants stated some skills as essentially contributing to their resilience. The themes that emerged during analysis pertaining to this topic include understanding role limitation and boundaries, acceptance of the attachment and separation in therapy, confronting and resolving personal issues before they start interfering with their work and competence. Research also suggests that incompetence is a major reason why people drop out of this profession. The skills suggested by the participants as contributing to their resilience are described below.

Understanding Role Limitations and Boundaries. Participants mentioned how important it was to be aware of one's responsibilities and duties and where one's boundary ends. Trying not to step into the boundaries of others was considered essential to earn respect and survive in the field.

As participant (P7) states,

"It is very important to understand your roles and accept your boundaries so that you do not step on the toes of your colleagues....And this ensures greater respect for you and for your field... Why tread on the path of others when you are not competent enough to do so? For example, with all my experience I have knowledge of the drugs prescribed for the disorders...now tomorrow if I start prescribing drugs to my patients even if I know that there is a need for medication and I know what medication to prescribe, I would never do that...I always refer him to the psychiatrist...Do what you are supposed to do, and do it well...only then can you survive in this field and earn the respect of others.

Participants also mentioned the value of establishing clear boundaries and limits in areas that included their role as a helper, the level of responsibility that they assumed, the structure of their practice and their relationship with their clients. The establishment of these boundaries enabled the practitioners to maintain a sense of wellbeing and vitality and to cope more effectively with difficult clients. To quote participant (P9),

"I am aware of my limited role as a therapist...I do not take things personally when they go wrong. Firstly, I make sure that I give in my 
best, and despite of that if something goes wrong, I do not take responsibility for it..."

Acceptance of the attachment and separation in therapy. Participants discussed their belief that attachments and separations in the therapeutic relationship followed a natural course, similar to those experienced in other relationships. This belief appears to help the participants accept therapeutic endings rather than letting them affect them. To quote participant (P5),

"Acceptance...Acceptance of the fact that your relationship with your clients won't be eternal...umm this should make you prepared for an ending... and I guess this is a good way to deal with counter transferences, if at all they surface..."

Confronting and resolving personal issues. Participants reported that their personal life crises and problems were a challenging area for them. They believed that direct acknowledgement and resolution of these issues allowed for congruence between the personal and professional self. One participant (P1) mentioned how her experience in dealing with the unexpected death of a family member challenged her at a profoundly personal level yet allowed her to be more attuned to her clients.

"Well, I think, suicide in my family has made the work challenging...and, at the same time, I found myself taking from that experience and just automatically moving it into what I was doing with my clients..."

Competence.All the ten participants mentioned the importance of constantly updating one's skills and knowledge and thus become more competent. Their lives were marked by an insatiable curiosity and constant consumption of knowledge.

To quote participant (P7),

"I tend to keep myself updated to prevent stagnancy. Now-a-days, clients tend to be equally aware of therapies and techniques; thanks to Google!"

Another participant discussed her efforts to bring new information at work (P10)

"When I read, I always know what I define as active learning, which is trying to take in the new information and see how I can incorporate it into 
what's already there and apply it on my clients... We also have presentations on a weekly basis, which help us updated on the recent research findings in the field."

\section{Extrinsic Factors contributing to Resilience}

This section highlights the extrinsic factors that contribute to resilience among psychotherapists. These factors include that are pertaining to the environmental factors that helped the participants continue in their profession. These categorizations are however not rigid and some sub themes do seem to be a part of both intrinsic and extrinsic factors.

\section{Work Settings}

Training. Six of the 10 participants attributed a part of their resiliency to the training that they had. They felt that the training equipped them to deal with occupational stressors that they would face later. The guidance provided was seen as beneficial by the participants.

To quote participant (P3),

"The training that I got from NIMHANS instilled in me the necessary skills, which taught me how to attach to a client and his problems with a sense of detachment. It also gave me the skills necessary for a successful therapist and a platform to practice and imbibe them"

As another participant (P6) puts it,

"I guess the greatest contributor to my resiliency is the learning experiences I had while doing my MPhil. It was great preparation in terms of the necessary skills required to face the real world. The two years that I spent doing my MPhil gave me rich and invaluable experience. It was like being taught to swim so before being thrown into the deep sea."

To quote another participant (P5),

"I had the liberty to make mistakes under the guidance of my professor. You do not have such privileges when you finish training and start practicing. The lessons learnt from those mistakes were invaluable."

Supervision. Eight out of the 10 participants mentioned discussed the importance of supervision, including peer supervision. They found supervision essential not just for discussing difficult cases, 
but also to talk about the work they do with clients. As P2 mentions,

"Supervision is important...even after so many years of working as a therapist, I still need supervision...to talk about clients, counter transference and also to talk about how life's in general..."

To quote another participant (P9),

"And also... discussing them (clients) with the supervisors helps me manage them more effectively, with lesser distress."

Peer relationship. All ten participants stressed the importance of developing positive relations with co workers as contributing to their resilience. They mentioned how one's colleagues can help one to deal with stress at one's work place

"We here constitute a big family! You may hear of tiffs between psychiatrists and psychologists. But nothing of that sort happens here. We work as a team, celebrating the success of our clients."(P3)

To mention another participant (P6)

"I think it is very important to develop and maintain a good relationship with your peers. If you are having a bad day at work, talking about it to them, sharing our experiences....having lunch together... makes a big difference."

P8 states how a relationship not only with your peers, but also with everyone in your work setting is important.

"Wishing a good morning to your security guard, enquiring whether your lift man had lunch.... these simple habits help in developing a good rapport with them... and then, a smile from them can elevate your mood on a bad day."

Vicarious Resilience. Vicarious resilience refers to how psychotherapists working with trauma survivors are affected by their resilience. It focuses on the psychotherapist's interpretation of the client's stories and how they make meaning out of them. (Hernandez,2007). Though not stated directly by the participants this phenomena was mentioned by six of the participants. To quote one of them,

"Instead of asking how I have become resilient, you should ask me how my clients have become resilient! There are rape victims, people who have lost 80 
all their family members to an accident, a natural disaster... and they still manage to smile...I can never forget this cancer patient who had come in the final stages of his disease...I mean, he was so calm and composed despite his illness and his sense of humor was something to be really appreciated, at this stage...Such clients in fact motivate me to work harder, make me grateful for my life which cannot even be compared to theirs..."(P7)

Benefits from the profession. Participants mentioned how the benefits they derive from the profession act as reinforcing agents and help them sustain in their profession. It is interesting to note that the participants continued in their profession for altruistic purposes as none of the ten participants mentioned money as a motivating factor.

In their book Leaving it at the Office, Norcoss and Guy (2007) cite the following as some of the rewards of practice: satisfaction of helping, freedom and independence, variety of experiences, intellectual stimulation, emotional growth, reinforcement for personality qualities, and life meaning. Some of the benefits that the participants derived from the profession are as follows:

Joy of helping and seeing participants change. Although there are no concrete measures of change as a result of psychotherapy, small noticeable changes in the clients were found to be reinforcing and very satisfying for the participants. It was something that As a participant (P9) mentions,

"The joy of helping someone in distress is heartening. To see their distress disappear, to help them make a difference, to see them change...wow it's just amazing...it's the best reward that you can get in this profession..."

Knowing that you played a significant role in helping people change. Apart from the joy of seeing people change as a result of psychotherapy, the fact that one has played a role in making that change was also a contributing factor for resilience among the participants. To quote participant (P4),

"I also have this strong need for attention (laughs) and this gets satisfied through my interaction with clients.... and success with a client can be intoxicating...once you have tasted that success, you would never want tom stop...it makes you stay back and yearn for more ..." 
To quote another participant (P7),

"I received an SMS on my birthday from one of my clients with whom I worked around 5 years ago. The card said that the only reason she is alive and living so happily is because of the work we did together. She was clinically depressed and suicidal for months."

A platform to express creativity. Participants stressed upon the uniqueness of their clients and their problems. Hence they have to adapt the theoretical knowledge to suit the specific problems of the client. Participants found this aspect of therapy interesting and as contributing to their sustenance in the profession. To quote a participant who found psychotherapy as offering opportunities to exercise his creative skills,

"I do a lot of things other than therapy such as photography, gardening, origami etc. However, I find my creative skills utilized most by psychotherapy. It gives me a platform to express my creativity." (P2)

Coping. As evident from the first global theme as well as previous literature, psychotherapy involves many occupational stressors. Participants in the current study mentioned about the various coping strategies that they use to deal with their occupational stressors.

Resilience and coping might seem to be similar, but there exists a distinction between the two. While one component of resilience is the use of effective coping strategies, such as task-focused coping, resilience includes many more equally important concepts (Luthans \& Youssef, 2007). These include a solid perception of reality, the ability to influence and improvise, a firm belief in the future, and numerous other components (Caverley, 2005; Coutu, 2002; Everall et al. 2006). Coping as a concept is built around negative events and how a person responds in these situations (Lazarus et al. 1980). The coping techniques that the participants mentioned during the interview are as follows.

Relationships with family and friend. Participants mentioned establishing and maintaining relationships with friends, family and other social groups. Although these relationships were essential on a day to day basis, they were especially critical in times of crisis. Some of the participants discussed how a network of supportive relationships fortified their lives. 
"Maintaining a work-family balance is crucial especially when your work is stressful. The family helps you bounce back from a tough day at work. It is equally important that you reciprocate the same to your family members." (P8)

Participating in non-professional activities. All the 10 participants mentioned engaging in at least one non-work activity which included hobbies like gardening, listening to music etc. Although the actual involvements are varied, a common theme that runs across the responses is that they provide diversion from work related stressors. To quote participant (P2),

"I engage in various other hobbies that act as buffers for me....reading, photography, and even cooking! They provide a break from work and keep my mind away from work related stressors. I guess it's necessary to engage in such activities to relax."

Research by Dlugos (2004) suggests that psychotherapists who participated in at least one no-work activity were able to maintain a sense of balance and wellness.

Spirituality. Participants mentioned that spirituality or having faith in a higher entity gave them hope and helped them through difficult situations. Thus it did not necessarily mean being religious. Two out of the 10 participants mentioned that spirituality contributes to their resilience. One participant also mentioned how it helped her to accept one's limitations and derive meaning from the profession. To quote her,

"It is very important to have a connection with something greater than you. Your role as a therapist is successful only when you see Him working through you in helping your clients. You realize that you are only an instrument operated by a greater power. Realizing this will help you shed your egos and derive more satisfaction and meaning from your profession." (P3)

Thus it can be seen that there are a host of factors- intrinsic and extrinsic- that contribute to therapist resilience, in spite of the occupational stressors they face. The themes described above also help us to answer the major research question: why some mental health professionals appear to handle the stress related to their profession well and sustain in their profession

The specific research objectives of understanding how mental health professionals adapt well to stresses generated by their 
profession and exploring intrinsic and extrinsic factors that enable mental health professionals cope with occupational stress have also been answered.

\section{Implications of the study}

The implications of the study extend to psychotherapists, supervisors, institutes training students in mental health as well as for the students who wish to pursue this profession.

Students contemplating a career in psychotherapy could reflect upon the factors contributing to resilience and assess whether they have those traits which contribute to resilience. Practicing psychotherapists can also apply these findings. Factors that are within the control of oneself can be modified and thereby helping them make better adaptations.

Employers who hire psychotherapists can also make use of the findings. If the characteristics can be identified during the selection process, it could prevent burnout and turnover. Also, the hiring agencies can modify the working environment to suit the needs of psychotherapists. Participants have mentioned how training contributed to their resilience. Hence institutes offering courses in mental health could also benefit from the findings. Factors contributing to resilience that can be learned could be incorporated into the curriculum. Perhaps this could result in a relative deemphasis of academic achievement priorities, and increased emphasis on screening for the personal characteristics contributing to resilience. Also a greater focus on skills that could help increase job satisfaction and resilience could be taught in these programs.

\section{Strengths of the Study}

The qualitative nature of the study contributed to a better understanding of resilience among psychotherapists as opposed to a quantitative one. The semi-structured interview format proved successful in guiding the interview without constraining the conversation with the interviewees.

The fact that theoretical saturation was attained indicates a comprehensive understanding of the topic. The credibility of the study is also a major strength. Peer validation and cross validation ensured that researcher bias did not affect the findings. 


\section{Limitations of Study}

The novel nature of the topic required an exploratory research, which did not allow for a controlling variable using an experimental design. This could assist in determining which of the identified characteristics are contributing to resilience. Without this comparison, it cannot be determined if the common elements discovered here are distinctive or unique to this group. Comparison groups for future research could include psychotherapists who have changed careers, psychotherapists who are burned out, or resilient individuals in helping professions outside the field of psychotherapy.

The number of years in practice ranged from 6 to 23. This could have played a role in contributing to resilience. This weakness could have been overcome with a substantially larger study group, controlling for such variables.

\section{Recommendations for further research}

As stated earlier, research studies using a quantitative approach, with a control group can be done to generalize factors contributing to resilience. A comparison of different mental health professionals: psychiatrists, psychotherapists, social workers, psychiatric nurses could be made to understand resilience in different contexts. Research could be developed for assessing the presence of these traits in individuals beginning a career in psychotherapy to determine whether or not they predict success and satisfaction in that role. Other interesting research could involve a comparison group of similarly identified resilient workers in fields unrelated to psychotherapy, to determine what resilient psychotherapists have in common, and in distinction to, other resilient professionals.

\section{Conclusion}

The current study aimed at exploring factors contributing to resilience among psychotherapists, attempting to answer how some psychotherapists seem to handle the stress of their profession well and continue in their profession. Thematic analysis of the transcribed interviews captured findings under three themes: 
occupational stressors, intrinsic factors contributing to resilience, and extrinsic factors contributing to resilience.

Given these results, further research that surpasses the limitations of this study could be conducted. Students, practitioners, employers who hire psychotherapists and institutions offering psychotherapy courses could benefit from an understanding of factors contributing to resilience among psychotherapists.

\section{References}

Alexander, S., Cristine P. (2011). Resilience among doctors who work in challenging areas: A qualitative study. British Journal of General Practice, 61 (588), pp. e404-e410(7)

American Psychological Association (2008) Fostering Resilience in Response to Terrorism Among Mental Health Workers. Retrieved on 29th June, 2011 from http://www.georgiadisaster.info/MentalHealth/ MH16\%20SecondaryStress/Fostering\%20Resilience\%20Mental\%20He alth\%20Workers.pdf

Antonovsky A. Unraveling the Mystery of Health. How People Manage Stress and Stay Well. San Francisco: Jossey-Bass; 1987.

Brown, B. (1996). Career resilience (Report No. 178), ERIC Clearinghouse on Teaching and Teacher Education

Chein, I. (1981). Appendix: An introduction to sampling. In L. H. Kidder (Ed.), Selltiz, Wrightsman \& Cook's research methods in social relations (4th ed.). Austin, TX: Holt, Rinehart and Winston.

Collard, B., Epperheimer, J., \& Saign, D. (1996). Resilience in a changing workplace. ERIC Clearinghouse on Adult, Career, and Vocational Education.

Johnston G (2006) Therapist Resilience in Trauma Work: 'Resistance is the Secret of Joy' Retrieved 29th June, 2011 from http://www.nzfvc.org.nz/accan/paperspresentations/abstract100v.shtml

Lazarus, R. (1993). From psychological stress to the emotions: A history of changing outlooks. Annual review of psychology, 44, 1-21.

Lazarus, R., \& Folkman, S. (1984). Stress, Appraisal and Coping. New York: Springer.

Liney, A.Joseph, S. (2007) Therapy Work and Therapists' Positive and Negative Well-being. Journal of Social and Clinical Psychology.26(3). pp $385-403$ 
Luthans, F. (2002b). Positive organizational behaviour: Developing and managing psychological strengths. Academy of Management Executive, $16,57-72$.

Luthans, F., \& Youssef, C. (2007). Emerging positive organizational behaviour. Journal of Management, 33(3), 321-349.

Rabin, S., Feldman, D., \& Kaplan, Z. (1999). Stress and intervention strategies in mental health professionals. British Journal of Medical Psychology, 72, 159-169.

Reivich, K., \& Shatt_, A. (2002). The Resilience Factor. New York: Broadway Books.

Richardson, G. (2002). The metatheory of resilience and resiliency. Journal of Clinical Psychology, 58(3), 307-321.

Richardson, G., Nieiger, B. Jenson, S., \& Kumpfer, K. (1990). The resiliency model. Health Education, 21(6), 33-39

Seligman, M.E.P. \& Csikszentmihalyi, M. (2000). Positive psychology: An introduction. American Psychologist, 55, 5-14.

Terry, D., \& Jimmieson, N. (2003). A stress and coping approach to organizational change: Evidence from three field studies. Australian Psychologist, 38(2), 92-101

Ungar, Michael (2003). Qualitative contributions to resilience research. Qualitative Social Work, 2; 85 pp 85-102.

Werner, E. (2005). Resilience and recovery: Findings from the Kauai longitudinal study. Focal Point, 19(1), 11-14.

Zur, O. (2011). Taking Care Of The Caretaker: How To Avoid Psychotherapists' Burnout. Online Publication by Zur Institute. Retrieved from http://www.zurinstitute.com/burnout.html 